Persistent Tardive Dyskinesia S. Brandon, M.D., D.P.M., and H. A. McClelland, M.R.C.P., D.P.M..........70

Survival in Severe Congenital Heart Disease

C. G. Parsons, F.R.C.P., and K. D. Roberts, F.R.C.S.; E. N. Coleman, F.R.C.P.ED.; E. T. O. Slater, F.R.C.P.................701

Practicalities of Nursing

J. C. M. Browne, F.R.C.o.G. . . . . . . 702

Oral Contraceptives, Depression, and Libido

W. F. O'Dwyer, F.R.C.P.I. . . . . . . . . . . .702

Possible Hazard in Use of Gentian Violet H. S. Rosenkranz, PH.D., and H. S. Carr, B.S. $\ldots \ldots \ldots \ldots \ldots \ldots \ldots \ldots \ldots \ldots \ldots \ldots 702$

Chromosome Breakage and Ultrasound

I. J. C. Macintosh, M.sc............703

Care of Chronic Psychotics

M. Z. Hussain, D.P.M., and A. G. Khan,

D.P.M. .....................
Levodopa and Anticholinergic Drugs in Parkinsonism

T. L. Sourkes, PH.D..............703

Accident and Emergency Services

D. B. McFarlane, M.B.............704

Mitotic Indices and Oral Contraceptives

N. P. Bishun, PH.D., and J. Mills, B.SC... . . . 704

Treatment of Myocardial Infarction

J. Pemberton, F.R.C.P. .

Brucellosis and Goat's Cheese?

Colonel E. E. Vella, M.D., F.R.C.PATH... . . . 705 Queen Alexandra and the Tate

D. C. Bowie, F.R.C.S.ED.; Sir Selwyn

Selwyn-Clarke, F.R.C.P...............705

Treating Asthma

A. P. Smith, M.R.C.P., and others.......705 Bullous Lesions in Poisoning

D. L. Harris, F.R.C.S..............706

Red Cell Size and Air Composition

Surgeon Commander R. J. W. Lambert,

D.P.H., and J. E. W. Morris..........706
Intermittent Claudication

H. G. S. Korvin, F.R.C.S. . . . . . . . 706

Reiter's Syndrome-Protean Symptoma-

tology?

K. R. Woodcock, M.R.C.P............706

Fluorescent Staining and Human IgM

K. B. Fraser, M.D., and others..........707

Future of the Species

S. L. H. Smith, D.T.M.\&H. . . . . . . . . 707

Long-term Haemodialysis without Blood

Transfusion or Drugs

H. Yatzidis, M.D., and others..........707

Social Services and Community Health

W. H. Parry, M.D., D.P.H.............708

Uses of Bureaucracy

W. S. Parker, D.P.H............... 708

Stilboestrol and Cancer

Sir Charles Dodds, F.R.C.P., F.R.S. . . . . . . 708
SIR,-The report by Dr. S. G. Carruthers (4 September, p. 572) of a case of persistent tardive dyskinesia apparently responding to treatment with thiopropazate is most interesting but requires some amplification and the author's comments cannot be allowed to pass unchallenged.

It is necessary to establish whether the patient's disabling dyskinesia developed or became exacerbated after the withdrawal of chlorpromazine, whether at the time of her accident or later she became hypoxic (as suggested for instance by clouding of consciousness or the development of bronchopneumonia), and whether the statement that the patient's memory was good was based upon a careful and comprehensive mental state examination or upon clinical impression. Brandon, McClelland, and Protheroe suggested that in some cases dyskinetic movements are an attempt to overcome the phenothiazine-induced blockade of the reticular arousal system by amplification of some afferent impulses, hence their occurrence on withdrawal and the occasional paradoxical improvement on increasing or reinstating the drug. They also reported the development of dyskinesia following hypoxia induced by poisoning or severe respiratory embarassment. From their survey of the resident population of a mental hospital they concluded that while exposure to phenothiazines, the presence of brain damage, and increasing length of stay in hospital all show some association with dyskinesia, increasing age and constitutional factors are probably more important in the genesis of movement disorders. In particular, they demonstrated that more than a quarter of all cases of tardive

dyskinesia have

With a disorder of such complexity it is important to avoid unfounded assumptions of cause and effect. In the case reported by Dr. Carruthers, age, cerebral disorder, psychiatric illness, or hospitalization, the administration or withdrawal of chlorpromazine, and sequelae of the hip injury were among the factors which may have been involved in the development of dyskinesia. The apparent increase in the prevalence of dyskinesia is related as much to its increased recognition as to changes in possible aetiological factors, and such movements were certainly evident in mental hospitals and other institutions before phenothiazines were available.

On the basis of present knowledge it is reasonable to advise that phenothiazines should be prescribed reluctantly in the aged or in the presence of cerebral disorder. When they are prescribed change or withdrawal should always be gradual and if dyskinesia does develop increasing or restoring the dose may diminish the movements. Perhaps we should also consider more frequent use of oxygen in bronchopneumonia and other conditions producing anoxia. It is clear however that we have not yet unravelled the pathogenesis of this syndrome. -We are, etc.,

University of Manchester

SYDNEY BRANDON

St. Nicholas Hospital,

Gosforth,

Newcastle-upon-Tyne 3

1 Brandon, S., McClelland, H. A., and Protheroe, C., British Fournal of Psychiatry, 1971, 118, 171 .

\section{Survival in Severe Congenital Heart Disease}

SIR,-Professor J. D. Hay's comments (4 September, p. 579) on your leading article (26 June, p. 723) are apt and we suppor his plea for an increase in staffing and resources to meet the demands on the paediatric cardiology service. Our experience in Birmingham highlights the effect of having not quite enough nurses to do the work.

For example, our cardiac theatre has no spare capacity. To keep abreast of the waiting list we must average four planned bypass operations each week-which means doing five or six by-pass operations a week for much of the time in addition to "ordinary" cardiac surgery and emergency operations on babies. (Approximately 200 babies are admitted to the unit for investigation and treatment each year.) This imposes a heavy strain on the theatre staff and if, for any reason, a nurse has to go off duty unexpectedly the programme comes to a halt.

The level of staffing in the intensive treatment unit is such that we are frequently forced to use agency nurses to prevent any hold up to the flow of patients. (Incidentally, medical cover in this area is also severely stretched.) A steady flow of patients depends also on being able to transfer patients into high dependency areas in the two cardiothoracic wards. But how can this be achieved when the night staff to look after a ward of 26 children may consist of a third-year student nurse with no paediatric experience and a nursing auxiliary? Yet if the flow of patients hesitates or stops the waiting list grows, high risk cases accumulate and standards, enthusiasm, and morale decline.

The obvious solution is to recruit more nurses. This can be difficult when conditions are known to be unsatisfactory. Anyway, we are in no position to recruit even unqualified staff because we are told that we cannot expect extra money from central funds for additional salaries-we have to make better use of the nurses already on our payroll. We cannot take nurses from other wards in the hospital because that would make it impossible for the paediatricians to do their work. We thought it might make for greater flexibility if nurses were allocated to the cardiothoracic service instead of to a 